Article

\title{
Rapid and Sensitive Determination of Timosaponin AIII in Rat Plasma by LC-MS/MS and Its Pharmacokinetic Application
}

\author{
Yanping Liu ${ }^{1,2}$, Yiqiong Pu ${ }^{2}$, Tong Zhang ${ }^{1, *}$, Yue Ding ${ }^{2, *}$, Bing Wang ${ }^{2}$ and Zhenzhen Cai ${ }^{2}$ \\ 1 School of Pharmacy, Shanghai University of Traditional Chinese Medicine, Shanghai 201203, \\ China; E-Mail: lyp1066@hotmail.com \\ 2 Experiment Center for Teaching and Learning, Shanghai University of Traditional Chinese Medicine, \\ Shanghai 201203, China; E-Mails: puyiq@hotmail.com (Y.P.); annabel_cn@163.com (B.W.); \\ Czz2021@vip.sina.com (Z.C.) \\ * Authors to whom correspondence should be addressed; E-Mails: zhangtdmj@yahoo.com.cn (T.Z.); \\ dingyue-2001@hotmail.com (Y.D.); Tel.: +86-21-5132-2318 (T.Z.); +86-21-5132-2323 (Y.D.); \\ Fax: +86-21-5132-2337 (T.Z.); +86-21-5132-2323 (Y.D.).
}

Received: 8 October 2012; in revised form: 5 December 2012 / Accepted: 30 January 2013 / Published: 7 February 2013

\begin{abstract}
A rapid sensitive and selective liquid chromatography-tandem mass spectrometry (LC-MS/MS) method was developed for determination of timosaponin AIII (TA-III) in rat plasma, using ginsenoside Re as an internal standard (IS). TA-III and the IS were detected in MRM mode with a negative ionization electrospray mass spectrometer. The calibration curves were linear over the concentration ranges from 11.14 to $1114 \mathrm{ng} / \mathrm{mL}$ and the lower limit of quantification (LLOQ) was $11.14 \mathrm{ng} / \mathrm{mL}$. Intra-day and inter-day precisions (RSD) were within $10 \%$, and accuracy ranged from $6.4 \%$ to $9.1 \%$. The extraction recovery at three concentrations ranged from $92.3 \%$ to $95.5 \%$. The validated method was successfully applied to monitor the concentrations of TA-III in rat plasma after intragastric administration. The best fit pharmacokinetic model to estimate the pharmacokinetic parameters was a single compartment model with weight of $1 / x^{2}$ for oral administration groups of rats for TA-III.
\end{abstract}

Keywords: timosaponin AIII; LC-MS/MS; rat plasma; pharmacokinetic study 


\section{Introduction}

Timosaponin AIII (TA-III) is a typical spirostanol saponin,originally isolated from the rhizome of Anemarrhena asphodeloides. It was reported that TA-III could ameliorate learning and memory deficits in mice [1]. Another studies showed that TA-III had remarkable anticancer activity [2,3] and anti-respiratory syncytial virus (RSV) properties [4], which were also revealed to be a pronounced activator of autophagy [5].

In view of its powerful pharmacological activities, it is very important to explore its pharmacokinetic behaviors, before which it is essential to develop a proper method to determine its concentration in plasma. There has been no report about the determination of TA-III in a biological matrix. In this paper, we aimed to establish a rapid, sensitive and selective liquid chromatography-tandem spectrometry (LC-MS/MS) method for the determination of TA-III in rat plasma. The analysis was achieved by using LC-MS/MS in negative ionization mode, and ginsenoside Re (IS) was employed as the internal standard (IS) [6]. The chemical structures of TA-III and ginsenoside Re were shown in Figure 1. The IS was found to have sensitive response, freed of interference with high recovery properties. TA-III and IS were identified and quantified by using multiple-reaction monitoring (MRM) mode, which enhanced the sensitivity and specificity of the analysis. The method was validated over the concentration range of $11.14-1140 \mathrm{ng} / \mathrm{mL}$. The method was successfully applied to the pharmacokinetic study of TA-III after oral administration in rats. This is the detail research report on the pharmacokinetic study of TA-III, which may have a great significance for further research and application.

Figure 1. (A) Chemical structure of TA-III, TA-III MW = 740.92; and (B) ginsenoside Re (internal standard), ginsenoside Re MW = 945.4.

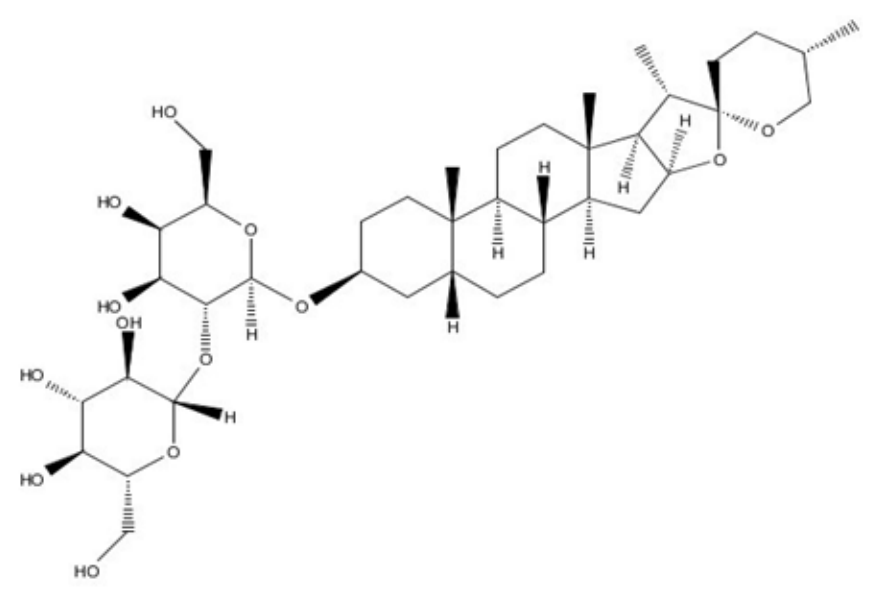

(A)

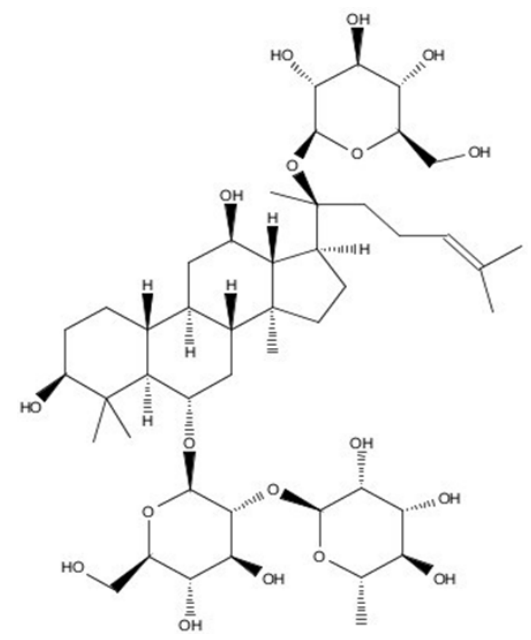

(B)

\section{Experimental Section}

\subsection{Chemicals and Reagents}

TA-III (Purity around 90\%) for animal experiments was isolated and purified from the rhizome of Anemarrhena asphodeloides in our laboratory. TA-III (purity $\geq 98 \%$ ) was purchased from Shanghai Yuanye Bio-Technology Co., Ltd., which was used as a reference standard compound for quantitative 
analysis of TA-III in biological samples. Its chemical structure was unambiguously identified by ESI-MS, ${ }^{1} \mathrm{H}-\mathrm{NMR}$, and ${ }^{13} \mathrm{C}-\mathrm{NMR}$ spectra [7]. ${ }^{1} \mathrm{H}-\mathrm{NMR}\left(\mathrm{C}_{5} \mathrm{D}_{5} \mathrm{~N}\right) \delta: 0.79\left(3 \mathrm{H}, \mathrm{s}, 18-\mathrm{CH}_{3}\right), 0.95(3 \mathrm{H}, \mathrm{s}$, $\left.19-\mathrm{CH}_{3}\right), 1.05\left(3 \mathrm{H}, \mathrm{d}, \mathrm{J}=7.1 \mathrm{~Hz}, 27-\mathrm{CH}_{3}\right), 1.13\left(3 \mathrm{H}, \mathrm{d}, \mathrm{J}=6.6 \mathrm{~Hz}, 21-\mathrm{CH}_{3}\right), 4.49(1 \mathrm{H}, \mathrm{d}, \mathrm{J}=7.7 \mathrm{~Hz}$, Gal 1-H), 5.27(1H, d, J = 7.7 Hz, GLC 1-H). ${ }^{13} \mathrm{C}-\mathrm{NMR}$ (DMSO) $\delta: 109.6,106.1,102.5,81.8,81.3$, 78.3, 78.0, 76.9, 76.5, 75.4, 75.1, 71.6, 69.8, 65.0, 62.9, 62.7, 62.1, 56.4, 42.4, 40.8, 40.2, 40.1, 36.9, $35.4,35.2,32.1,30.8,30.8,27.5,26.9,26.7,26.7,26.3,26.1,23.9,21.0,16.5,16.2,14.8$. The internal standard (IS), ginsenoside Re (98\% purity) was also purchased from the Shanghai Yuanye Bio-Technology Co., Ltd (Shanghai, China). Acetonitrile (HPLC grade) was obtained from Merck (Darmstadt, Germany). All other reagents were of analytical grade.

\subsection{Instruments and Analytical Conditions}

\subsubsection{Instruments}

The analyses were performed on an Agilent 1290 Series high-performance liquid chromatography (HPLC) system (Agilent, USA), equipped with a G4220A binary pump, a G4226A autosampler and a G1316C thermosttated column compartment. An Agilent 6460A Triple Quad LC/MS equipped with an electrospray source was connected to the HPLC system. An Agilent Eclipse XDB-C $\mathrm{C}_{18}$ column $(50 \mathrm{~mm} \times 2.0 \mathrm{~mm}, 1.8 \mu \mathrm{m})$ was used for liquid chromatographic separation.

\subsubsection{Analytical Conditions}

The mobile phase was consisted of water and acetonitrile using gradient elution. The column was equilibrated and eluted under gradient conditions (shown in Table 1) with a flow rate of $0.4 \mathrm{~mL} / \mathrm{min}$, maintained at $25^{\circ} \mathrm{C}$. The sample injection volume was $5 \mu \mathrm{L}$.

The mass conditions of electrospray ionization were optimized as follows: Capillary $-4500 \mathrm{~V}$, gas temperature $350{ }^{\circ} \mathrm{C}$, drying gas $10 \mathrm{~L} / \mathrm{min}$. Quantification was performed in negative multiple reaction monitoring (MRM). The optimized MRM parameters for TA-III and IS were shown in Table 2. Full scan product ion of precursor ions of TA- III and IS were shown in Figure 2 and 3.

Table 1. HPLC-MS/MS mobile phase gradient elution condition.

\begin{tabular}{cccc}
\hline Time (min) & $\mathbf{A}\left(\mathbf{H}_{\mathbf{2}} \mathbf{O}\right)$ & $\mathbf{D}$ (Acetonitrile) & Flow (mL/min) \\
\hline 0 & $85 \%$ & $15 \%$ & 0.4 \\
0.5 & $85 \%$ & $15 \%$ & 0.4 \\
6.0 & $10 \%$ & $90 \%$ & 0.4 \\
7.0 & $10 \%$ & $90 \%$ & 0.4 \\
7.1 & $85 \%$ & $15 \%$ & 0.4 \\
9 & $85 \%$ & $15 \%$ & 0.4 \\
\hline
\end{tabular}

Table 2. Optimized multiple-reaction monitoring (MRM) parameters for Timosapoin AIII and ginsenoside Re (IS).

\begin{tabular}{ccccc}
\hline Sample Name & Precursor/Product Ion & Dwell (msec) & Fragmentor & CE \\
\hline Timosapoin AIII & $739.2 / 577.2$ & 200 & 260 & 30 \\
Ginsenoside Re & $945.4 / 475.2$ & 200 & 280 & 60 \\
\hline
\end{tabular}


Figure 2. Production spectra of Timosapoin AIII.

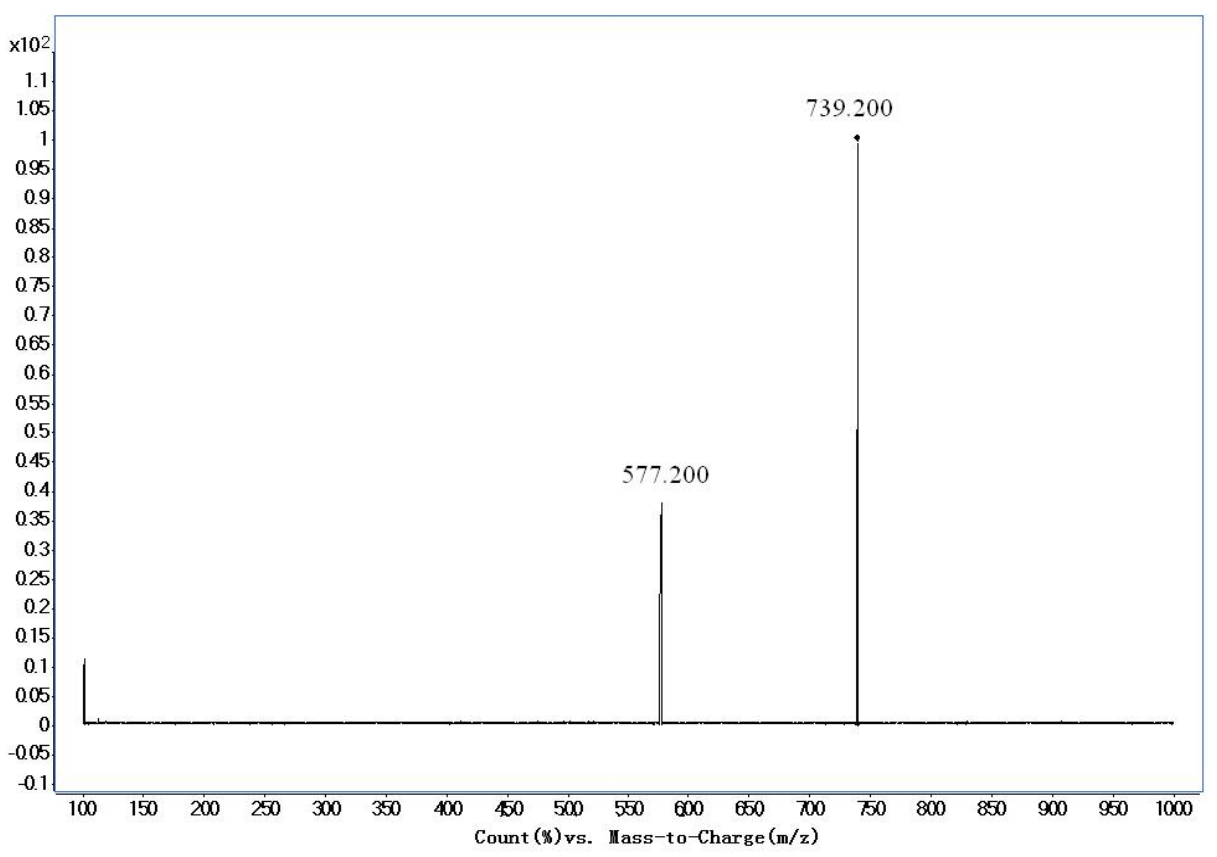

Figure 3. Production spectra of ginsenoside Re (IS).

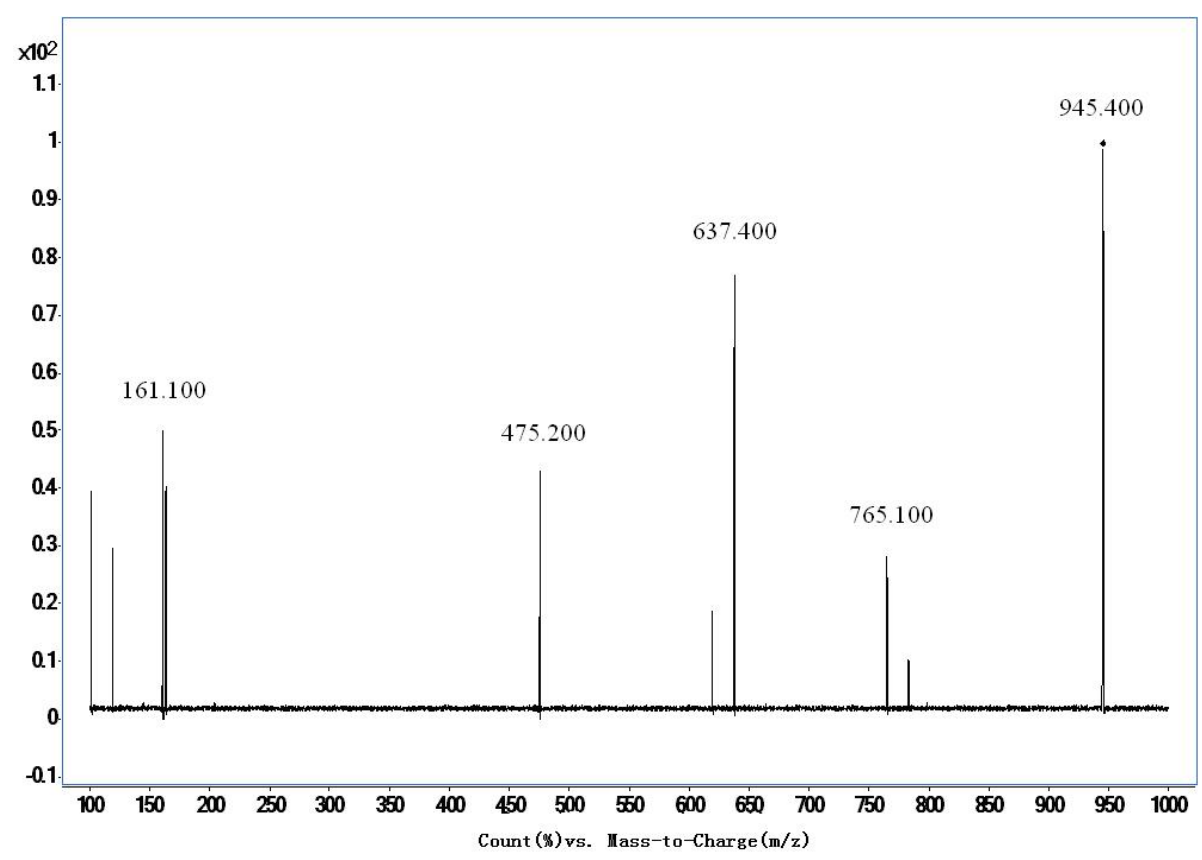

\subsection{Sample Preparation}

A simple and rapid protein precipitation method was used for the preparation of plasma samples. $20 \mu \mathrm{L}$ IS solution $(7.4 \mu \mathrm{g} / \mathrm{mL})$ and $300 \mu \mathrm{L}$ methanol were added to $100 \mu \mathrm{L}$ plasma sample. After vortexes for $5 \mathrm{~min}$ and centrifuged at $17,000 \times \mathrm{g}$ for $10 \mathrm{~min}$, all of the supernatant was transferred to a clean $1.5 \mathrm{~mL}$ centrifuge tube and evaporated to dryness under nitrogen. The obtained dried extract was reconstituted in $100 \mu \mathrm{L}$ methanol by vortex-mixing for $5 \mathrm{~min}$. Then the extracted sample was centrifuged at $19,000 \times \mathrm{g}$ for $10 \mathrm{~min}$. The supernatant was transferred into injector vials and a $5 \mu \mathrm{L}$ aliquot was injected into LC-MS/MS system for analysis. 


\subsection{Animals and Pharmacokinetic Study}

Male Sprague-Dawley rats $(225 \pm 25 \mathrm{~g})$ were supplied by the Shanghai Experiment Animal Center and housed in an air-conditioned animal quarter at a temperature of $22-24{ }^{\circ} \mathrm{C}$ and the relative humidity of $50 \% \pm 10 \%$. They had free access to rodent chow and tap water prior to the experiments. Rats were fasted $12 \mathrm{~h}$ with free access to water prior to the test. Fifteen rats were randomly divided into three groups. An aqueous solution contained TA-III was intragastrically administrated to rats, respectively at doses of 25, 50 , and $75 \mathrm{mg} / \mathrm{kg}$, and the volume of administration was $1 \mathrm{~mL} / 100 \mathrm{~g}$. Blood samples (in each case approximately $0.3 \mathrm{~mL}$ ), collected in heparinized tubes via the postorbital venous plexus veins from rats at $0.5,1,2,4,6,7,8,10,12,14,24,27,30,36,48 \mathrm{~h}$ after administration, were immediately centrifuged at $5000 \times \mathrm{g}$ for $5 \mathrm{~min}$ to obtain the plasma. The samples were then pretreated with exactly the same procedure as described in Section 2.3. Plasma samples collected from 15 rats before administration were served as blank control samples. Animal experiments were carried out in accordance with the local institutional guidelines for animal care of Shanghai University of Traditional Chinese Medicine.

\subsection{Method Validation}

\subsubsection{Selectivity}

The selectivity of the method was investigated by analyzing six individual blank plasma samples. The chromatographic findings of each control drug-free plasma containing neither analyte nor internal standard (double blank) were compared with the spiked rat plasma containing TA-III $(557 \mathrm{ng} / \mathrm{mL})$ and IS (1480 ng/mL) and the plasma sample was collected at $0.5 \mathrm{~h}$ after an oral dose of $50 \mathrm{mg} / \mathrm{kg}$ TA-III to check the absence of interference.

\subsubsection{Linearity and Lower Limit of Quantification (LLOQ)}

The stock standard solutions of TA-III and IS were prepared by dissolving accurately weighed individual compounds in volumetric flasks with methanol to give a final concentration of 5.57 and $7.40 \mathrm{mg} / \mathrm{mL}$, respectively. A series of standard working solutions at concentrations of 11.14-1140 ng/mL for TA-III were obtained by adequate dilution of the standard stock solution with methanol. IS working solution $(7.40 \mathrm{ng} / \mathrm{mL})$ was prepared by diluting its stock solution with methanol. All solutions were stored at $4{ }^{\circ} \mathrm{C}$ and brought to room temperature $\left(20^{\circ} \mathrm{C}\right)$ before use.

One hundred microliter of a series of standard solution of TA-III were transferred to a $1.5 \mathrm{~mL}$ centrifuge tube and evaporated to dryness under nitrogen. Then, $100 \mu \mathrm{L}$ of blank plasma was added respectively, vortexed for $5 \mathrm{~min}$, to obtain standard working solutions at concentrations of 11.14, 55.7, $111.4,278.5,557$ and $1140 \mathrm{ng} / \mathrm{mL}$. Then, the samples were pretreated with exactly the same procedure as described in Section 2.3. Each concentration level was prepared in six replicates. To evaluate linearity, plasma calibration curves were prepared and assayed in duplicate on six consecutive days over the range $11.4-1140 \mathrm{ng} / \mathrm{mL}$ for TA-III with the same concentration $(1480 \mathrm{ng} / \mathrm{mL})$ for IS. The contents of TA-III in the test samples were calculated using the regression parameters obtained from the standard curve. The acceptance criteria for a calibration curve were that each back-calculated standard concentration must be within $15 \%$ deviation from the nominal value except at the LLOQ, for 
which maximum acceptable deviation was set at 20\%. The LLOQ was defined as the lowest concentration that gave a signal-to-noise ratio $(\mathrm{S} / \mathrm{N})$ of $\geq 10$. The LOD demonstrated that the concentration that gave a signal-to-noise ratio $(\mathrm{S} / \mathrm{N})$ of 3 .

\subsubsection{Precision and Accuracy}

Three concentrations (11.14, 557 and $1114 \mathrm{ng} / \mathrm{mL})$ of TA-III standard solutions were added to blank plasma to obtain quality control samples (QC Samples), respectively. Six replicates of each QC samples were prepared to determine on the same day for intra-day and on six consecutive days for the inter-day accuracy validation. The concentrations were calculated using calibration curves obtained on the day. The precision of the method at each QC concentration was expressed as the relative standard deviation (RSD) and the accuracy was described as relative error (RE), i.e., (determined concentration-nominal concentration $) /($ nominal concentration $) \times 100 \%$. The acceptance criteria for precision and accuracy were that RSD should be within $15 \%$ and the RE should be within $15 \%$ of the actual values for QC samples.

\subsubsection{Extraction Recovery}

The three concentration-spiked $(11.14,557$ and $1114 \mathrm{ng} / \mathrm{mL})$ plasma samples containing TA-III were prepared, and then pretreated with exactly the same procedure as described in Section 2.3. Each level was pretreated in six replicates. At the same time, $100 \mu \mathrm{L}$ standard solution of TA-III $(11.14,557$ and $1114 \mathrm{ng} / \mathrm{mL})$, together with $20 \mu \mathrm{L}$ standard solution of IS $(7.4 \mu \mathrm{g} / \mathrm{mL})$, were respectively transferred to a $1.5 \mathrm{~mL}$ centrifuge tube, and evaporated to dryness under nitrogen. Then, $100 \mu \mathrm{L}$ post-preparative blank plasma was added respectively to redissolve. Each concentration level was prepared in six replicates. The recoveries (extracted recovery) of TA-III from rat plasma after the extraction procedure were determined by comparing the peak areas of extracted TA-III or IS in spiked plasma sample with the area of TA-III or IS of the same concentration level dissolved in the post-preparative blank plasma (the final solution of blank plasma after extraction and dissolution with the initial mobile phase solution).

\subsubsection{Analyte Stability}

Six replicates of QC samples $(11.14,557,1114 \mathrm{ng} / \mathrm{mL})$ were used to evaluate the stabilities of the analytes in rat plasma under the following storage conditions: post-preparative stabilities at room temperature for $24 \mathrm{~h}$, stabilities of unpreparative stabilities at room temperature for $24 \mathrm{~h}$, three freeze-thaw cycles and long-term stability storage at $-20{ }^{\circ} \mathrm{C}$ for 50 days. Concentrations of TA-III in all samples were calculated by using freshly prepared calibration samples. The stability was described as relative error, i.e., (determined concentration-nominal concentration)/(nominal concentration) $\times 100 \%$. The RE should meet the following criteria: not more than $15 \%$ deviation for the three different concentration QC samples.

\subsubsection{Post-Preparative Stabilities at Room Temperature for $24 \mathrm{~h}$}

Three QC samples $(11.14,557,1114 \mathrm{ng} / \mathrm{mL})$ were pretreated with exactly the same procedure as described in Section 2.3, at room temperature $\left(25^{\circ} \mathrm{C}\right)$ for $24 \mathrm{~h}$, to evaluate the post-preparative stabilities at room temperature. Each concentration level was prepared in six replicates. 


\subsubsection{Stabilities of Unpreparative Sample at Room Temperature for $24 \mathrm{~h}$}

Three QC samples $(11.14,557,1114 \mathrm{ng} / \mathrm{mL})$ were placed at room temperature $\left(25^{\circ} \mathrm{C}\right)$ for $24 \mathrm{~h}$, then pretreated with exactly the same procedure as described in Section 2.3, to evaluate the stabilities of unpreparative sample at room temperature. Each concentration level was prepared in six replicates.

\subsubsection{Three of Freeze-Thaw Cycles}

Three QC samples $(11.14,557,1114 \mathrm{ng} / \mathrm{mL})$ were detected after the three freeze-thaw cycles at $-20{ }^{\circ} \mathrm{C}$. Each concentration level was prepared in five replicates.

\subsubsection{Long-Term Stability Storage at $-20^{\circ} \mathrm{C}$ for 50 days.}

Three QC samples $(11.14,557,1114 \mathrm{ng} / \mathrm{mL})$ were stored at $-20{ }^{\circ} \mathrm{C}$, detected on the first and 50th day. Each concentration level was prepared in five replicates.

\subsubsection{Matrix Effect}

To evaluate the absolute matrix effect on the ionization of TA-III and IS, the peak areas of the compounds dissolved in the blank samples with three concentrations of TA-III (11.14, 557, $1114 \mathrm{ng} / \mathrm{mL})$ and IS (1480 $\mathrm{ng} / \mathrm{mL})$ were compared with those of the compounds only dissolved in methanol. The corresponding peak areas of TA-III or IS in spiked plasma post-extraction (A) were then compared with those of the solution standards in methanol (B) at equivalent concentrations. The ratio $(\mathrm{A} / \mathrm{B} \times 100 \%)$ is defined as the absolute matrix effect.

\subsection{Statistical Analysis}

To determine the pharmacokinetic parameters of TA-III, the concentration-time data were analyzed by DAS Software (version 2.0, China State Drug Administration). Data was expressed as means \pm SD.

\section{Method Validation}

\subsection{Selectivity}

The representative MRM chromatograms of plasma sample collected at $0.5 \mathrm{~h}$ after an oral dose of $50 \mathrm{mg} / \mathrm{kg}$ TA-III, blank rat plasma and spiked plasma $(n=6)$ were shown in Figure 4. The retention time was about $4.14 \mathrm{~min}$ for TA-III and $2.16 \mathrm{~min}$ for ginsenoside Re (IS). As shown in Figure 4, no interfering peaks were observed in the representative chromatogram of blank plasma at the retention time of TA-III or IS.

\subsection{Linearity and Lower Limit of Quantification (LLOQ)}

The calibration curve was obtained from the peak-area ratios of each analyte to IS versus plasma concentrations using a $1 / x^{2}$ weighted linear least-squares regression model. The calibration curve for spiked rat plasma of TA-III was $y=0.0021 x+0.1111(r=0.9960, n=6)$, linear over the range 
11.14-1114 ng/mL, with a correlation coefficient $r^{2}>0.99$. The date was shown in Table 3 . The lower limit of quantification (LLOQ) of TA-III in plasma was $11.14 \mathrm{ng} / \mathrm{mL}$.

Figure 4. Representative MRM chromatograms of TA-III and IS for (A) a plasma sample from a rat subject collected at $0.5 \mathrm{~h}$ after an oral dose of $50 \mathrm{mg} / \mathrm{kg}$ TA-III; (B) a blank rat plasma; (C) a spiked sample at the concentration of $557.0 \mathrm{ng} / \mathrm{mL}$ for TA-III and $1480 \mathrm{ng} / \mathrm{mL}$ for IS.

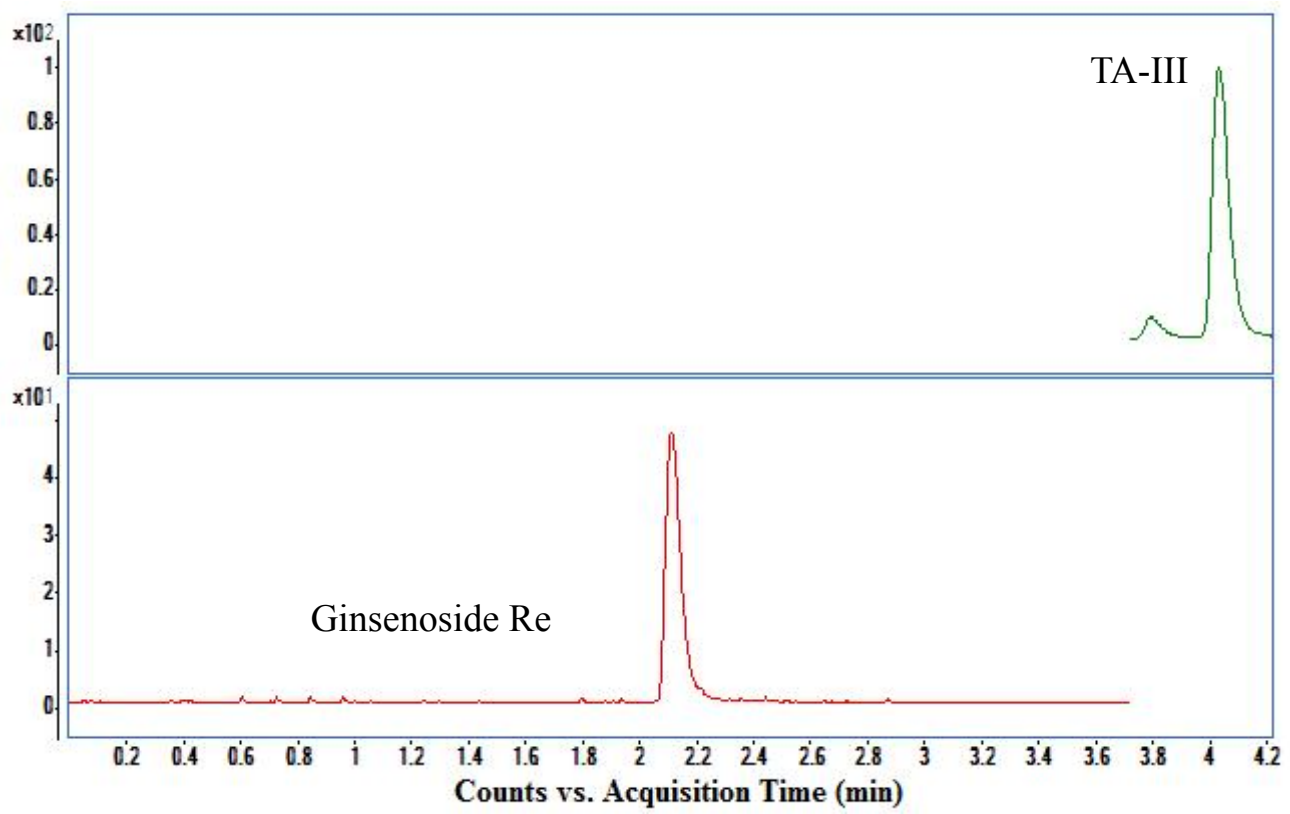

(A)

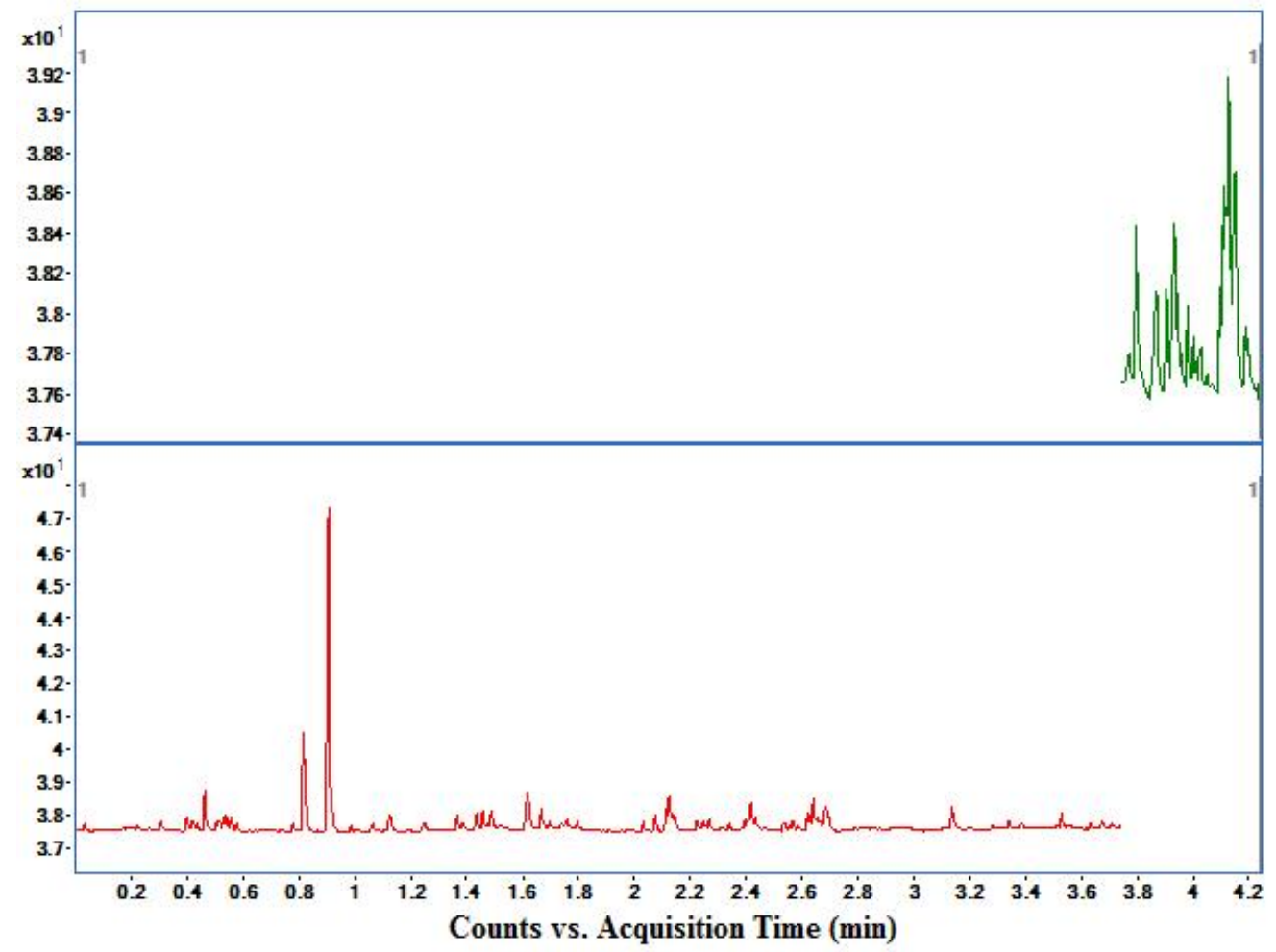

(B) 
Figure 4. Cont.

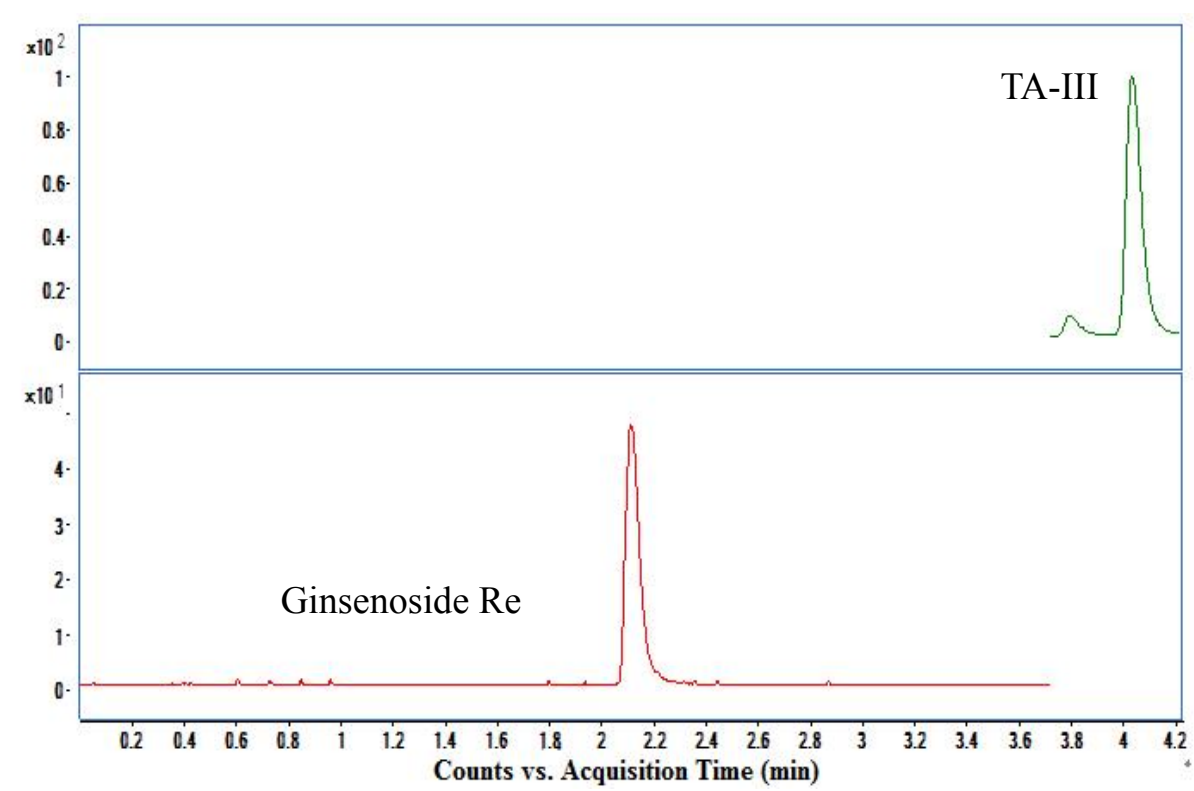

(C)

Table 3. Calibration curve of TA-III.

\begin{tabular}{ccccccc}
\hline Concentrations $(\mathbf{n g} / \mathbf{m L})$ & $\mathbf{1 1 . 1 4}$ & $\mathbf{5 5 . 7}$ & $\mathbf{1 1 1 . 4}$ & $\mathbf{2 7 8 . 5}$ & $\mathbf{5 5 7}$ & $\mathbf{1 1 1 4}$ \\
\hline Peak- area ratios $(n=6)$ & 0.0526 & 0.2105 & 0.4075 & 0.7726 & 1.2768 & 2.4608 \\
Calibration curve & \multicolumn{5}{c}{$y=0.0021 x+0.1111(r=0.9960, n=6)$} \\
\hline
\end{tabular}

\subsection{Precision and Accuracy}

The results of intra- and inter-day precisions and accuracies at three concentrations of TA-III were listed in Tables 4-6. The intra-day precisions ranged from 3.4\% to 7.8\%, while the inter-day precisions ranged from $2.7 \%$ to $3.5 \%$. Accuracy was determined as the percentage difference between the mean concentrations detected and the nominal concentrations. The accuracy derived from QC samples ranged from $6.4 \%$ to $9.1 \%$. The results demonstrated that this method had satisfactory accuracy and precision.

Table 4. Intra-day precision for the analysis of TA-III $(n=6)$.

\begin{tabular}{ccccccccc}
\hline Concentration $(\mathbf{n g} / \mathbf{m L})$ & $\mathbf{1}$ & $\mathbf{2}$ & $\mathbf{3}$ & $\mathbf{4}$ & $\mathbf{5}$ & $\mathbf{6}$ & AVE & RSD (\%) \\
\hline 11.14 & 10.5 & 10.7 & 10.9 & 10.9 & 11.4 & 12.9 & 11.2 & 7.8 \\
557 & 593.3 & 554.8 & 580.6 & 602.4 & 558.5 & 562.8 & 575.4 & 3.4 \\
1114 & 1143.3 & 1137.0 & 1108.6 & 1101.0 & 1036.9 & 1065.0 & 1098.0 & 3.8 \\
\hline
\end{tabular}

Table 5. Inter-day precision for the analysis of TA-III $(n=6)$.

\begin{tabular}{ccccccccc}
\hline Concentration $\mathbf{( n g / m L )}$ & $\mathbf{1 d}$ & $\mathbf{2 d}$ & $\mathbf{3 d}$ & $\mathbf{4 d}$ & $\mathbf{5 d}$ & $\mathbf{6 d}$ & AVE & RSD (\%) \\
\hline 11.14 & 11.2 & 11.1 & 11.1 & 11.1 & 11.0 & 11.9 & 11.2 & 3.0 \\
557 & 575.4 & 536.5 & 571.4 & 577.9 & 561.8 & 566.9 & 566.5 & 2.7 \\
1114 & 1098.0 & 1081.4 & 1085.4 & 1072.7 & 1042.3 & 1166.0 & 1092.0 & 3.5 \\
\hline
\end{tabular}


Table 6. Accuracy for the analysis of TA-III $(n=6)$.

\begin{tabular}{cccccccc}
\hline $\begin{array}{c}\text { Concentration } \\
(\mathbf{n g} / \mathbf{m L})\end{array}$ & $\mathbf{1}$ & $\mathbf{2}$ & $\mathbf{3}$ & $\mathbf{4}$ & $\mathbf{5}$ & $\mathbf{6}$ & $\begin{array}{c}\text { AVE } \\
\mathbf{( \% )}\end{array}$ \\
\cline { 2 - 7 } & 6.4 & 12.2 & 11.3 & 4.3 & 4.1 & 11.5 & 9.1 \\
557 & 5.8 & 5.0 & 1.3 & 9.2 & 10.9 & 11.4 & 7.3 \\
1114 & 4.8 & 11.3 & 10.4 & 0.3 & 6.6 & 5.0 & 6.4 \\
\hline
\end{tabular}

\subsection{Extraction Recovery}

Extraction recovery was determined at three QC levels $(11.14,557$ and $1114 \mathrm{ng} / \mathrm{mL})$ by comparing peak areas obtained from plasma samples with those obtained by direct assay of a standard solution with the same concentration. The results were shown in Table 7 . The extraction recovery of TA-III at three different concentrations ranged from $92.3 \%$ to $95.5 \%$. These statistic data indicated that the extent of recovery of TA-III and IS was consistent, precise and reproducible.

Table 7. Extraction recovery of TA-III from spiked rat plasma $(n=6)$.

\begin{tabular}{|c|c|c|c|c|c|c|c|c|}
\hline \multirow{2}{*}{$\begin{array}{c}\text { Sample } \\
\text { Concentration }(\mathrm{ng} / \mathrm{mL})\end{array}$} & \multirow{2}{*}{\multicolumn{6}{|c|}{ Extract recovery (\%) }} & \multirow{3}{*}{$\begin{array}{c}\text { AVE (\%) } \\
93.5\end{array}$} & \multirow{3}{*}{$\begin{array}{c}\text { RSD (\%) } \\
3.9\end{array}$} \\
\hline & & & & & & & & \\
\hline 11.14 & 93.6 & 93.8 & 99.6 & 96.1 & 89.5 & 88.4 & & \\
\hline 557 & 83.2 & 93.2 & 92.5 & 94.4 & 94.0 & 96.4 & 92.3 & 5.0 \\
\hline 1114 & 95.6 & 97.5 & 97.1 & 97.2 & 96.2 & 89.6 & 95.5 & 1.2 \\
\hline
\end{tabular}

\subsection{Analyte Stability}

Concentrations of TA-III in all samples were analyzed by using freshly prepared calibration samples. The stability was described as relative error, i.e., (determined concentration-nominal concentration $) /($ nominal concentration $) \times 100 \%$. The results met the following criteria: not more than $15 \%$ deviation for the three different concentration QC samples. The stability data were shown in Tables 8 , 9, 10 and 11. It indicated that the three analytes in plasma were stable under a variety of storage conditions: post-preparative and unpreparative at room temperature for $24 \mathrm{~h}$, at $-20{ }^{\circ} \mathrm{C}$ for 50 days and three of freeze-thaw cycles, with the average deviations being within $15 \%$ of the nominal values.

Table 8. Post-preparative stabilities at room temperature for $24 \mathrm{~h}(n=6)$.

\begin{tabular}{ccccccccc}
\hline Concentration (ng/mL) & $\mathbf{1}$ & $\mathbf{2}$ & $\mathbf{3}$ & $\mathbf{4}$ & $\mathbf{5}$ & $\mathbf{6}$ & AVE & RE (\%) \\
\hline 11.14 & 10.8 & 11.4 & 11.4 & 11.1 & 11.5 & 11.2 & 11.2 & 0.8 \\
557 & 600.7 & 592.4 & 603.7 & 588.7 & 621.9 & 566.9 & 595.7 & 6.9 \\
1114 & 1135.0 & 1153.7 & 1076.2 & 1062.6 & 1152.3 & 1081.9 & 1110.3 & 3.3 \\
\hline
\end{tabular}

Table 9. Unpreparative stabilities at room temperature for $24 \mathrm{~h}(n=6)$.

\begin{tabular}{ccccccccc}
\hline Concentration (ng/mL) & $\mathbf{1}$ & $\mathbf{2}$ & $\mathbf{3}$ & $\mathbf{4}$ & $\mathbf{5}$ & $\mathbf{6}$ & AVE & RE (\%) \\
\hline 11.14 & 10.2 & 10.6 & 11.4 & 11.7 & 11.2 & 11.7 & 11.1 & 0.2 \\
557 & 582.4 & 512.3 & 582.0 & 583.8 & 559.5 & 580.7 & 566.8 & 1.7 \\
1114 & 1149.1 & 1076.6 & 1066.7 & 1131.9 & 1073.3 & 1070.2 & 1094.6 & 1.7 \\
\hline
\end{tabular}


Table 10. Stabilities of three of freeze-thaw cycles $(n=6)$.

\begin{tabular}{ccccccccc}
\hline Concentration (ng/mL) & $\mathbf{1}$ & $\mathbf{2}$ & $\mathbf{3}$ & $\mathbf{4}$ & $\mathbf{5}$ & $\mathbf{6}$ & AVE & RE (\%) \\
\hline 11.14 & 10.9 & 10.6 & 11.0 & 10.6 & 10.9 & 12.1 & 11.0 & 1.0 \\
557 & 560.4 & 547.0 & 547.2 & 524.5 & 553.6 & 563.7 & 549.4 & 1.4 \\
1114 & 969.8 & 1091.1 & 984.6 & 1007.6 & 1018.7 & 996.3 & 1011.4 & 9.2 \\
\hline
\end{tabular}

Table 11. Long-term stability storage at $-20{ }^{\circ} \mathrm{C}$ for 50 days $(n=6)$.

\begin{tabular}{ccccc}
\hline Concentration (ng/mL) & $\mathbf{1}$ day & 50 days & AVE & RE (\%) \\
\hline 11.14 & 11.9 & 11.2 & 11.6 & 3.3 \\
557 & 566.9 & 564.3 & 565.6 & 1.5 \\
1114 & 1166.0 & 1096.9 & 1131.5 & 1.6 \\
\hline
\end{tabular}

\subsection{Matrix Effect}

The peak area of the post-extraction blank plasma spiked with standard solution of TA-III and IS was known as set 1, and the peak area of the diluted standard solutions in methanol at the same concentration was known as set 2 . Calculate the peak-area ratio of the analytes in set 1 with that in set 2. The results are shown in Table 12 . The matrix effects were no less than $85 \%$ or more than $115 \%$ for all the five analytes, which showed no significant difference between the peak areas of samples prepared from rat plasma and standard solution. It indicated that the matrix effect had no significant influence on the determination of TA-III in rat plasma.

Table 12. Matrix effect of TA-III in rat plasma $(n=5)$.

\begin{tabular}{cccccccc}
\hline Sample & \multicolumn{7}{c}{ Matrix Effect of TA-III (\%) } \\
\hline Concentration (ng/mL) & 1 & 2 & 3 & 4 & 5 & AVE (\%) & RSD (\%) \\
11.14 & 112.8 & 106.1 & 106.0 & 110.4 & 104.0 & 107.9 & 3.4 \\
557 & 110.2 & 107.8 & 92.2 & 113.6 & 115.0 & 107.8 & 8.5 \\
1114 & 105.3 & 109.8 & 99.3 & 97.7 & 97.5 & 101.9 & 5.3 \\
\hline
\end{tabular}

\section{Pharmacokinetic Analysis}

The results of the concentration time at the three doses of TA-III were shown in Tables 13-15. The mean plasma concentration-time curves were illustrated in Figure 5. The pharmacokinetic parameters were estimated by DAS software. The corresponding pharmacokinetic parameters were listed in Tables 16-19.

Table 13. Concentration time of TA-III after intragastrical administration to rats at a dose of $25 \mathrm{mg} / \mathrm{kg}(\mathrm{ng} / \mathrm{mL})$.

\begin{tabular}{cccccccc}
\hline Time (h) & Rat 1 & Rat 2 & Rat 3 & Rat 4 & Rat 5 & AVE & SD \\
\hline 0.5 & $3.7 *$ & 0.0 & $0.4 *$ & $1.5 *$ & 12.2 & $3.5 *$ & 1.42 \\
1 & 17.2 & $3.1 *$ & $6.1 *$ & 13.7 & 17.8 & 11.6 & 0.57 \\
2 & 42.0 & 58.9 & 18.6 & 47.0 & 44.7 & 42.2 & 0.35 \\
4 & 95.0 & 90.5 & 54.1 & 82.6 & 98.6 & 84.2 & 0.21 \\
6 & 95.4 & 97.5 & 62.7 & 127.2 & 86.9 & 93.9 & 0.25 \\
\hline
\end{tabular}


Table 13. Cont.

\begin{tabular}{cccccccc}
\hline Time (h) & Rat 1 & Rat 2 & Rat 3 & Rat 4 & Rat 5 & AVE & SD \\
\hline 7 & 100.7 & 91.3 & 93.2 & 131.0 & 106.3 & 104.5 & 0.15 \\
8 & 37.7 & 32.7 & 28.4 & 89.0 & 16.7 & 40.9 & 0.68 \\
10 & 33.9 & 22.8 & 25.9 & 25.3 & $9.7 *$ & 23.5 & 0.37 \\
12 & 18.4 & 13.1 & 42.3 & 39.4 & $11.0 *$ & 24.8 & 0.60 \\
14 & 12.3 & $9.7 *$ & 47.4 & 34.5 & 16.4 & 24.1 & 0.67 \\
24 & $6.6 *$ & $8.4 *$ & 31.8 & 21.7 & $11.1 *$ & 15.9 & 0.67 \\
27 & $3.5 *$ & $3.9 *$ & 24.5 & 13.1 & $1.5 *$ & $9.3 *$ & 1.03 \\
30 & $5.9 *$ & $3.8 *$ & 11.6 & $4.1 *$ & $0.2 *$ & $5.1 *$ & 0.81 \\
36 & $1.9 *$ & $0.5 *$ & 13.0 & $11.3 *$ & $0.5 *$ & $5.4 *$ & 1.14 \\
48 & $0.2 *$ & $1.4 *$ & $7.7 *$ & $1.9 *$ & $0.0 *$ & $2.2 *$ & 1.40 \\
\hline \multicolumn{7}{c}{ * Represents the detected concentrations below LLOQ. }
\end{tabular}

Table 14. Concentration time of TA-III after intragastrical administration to rats at a dose of $50 \mathrm{mg} / \mathrm{kg}(\mathrm{ng} / \mathrm{mL})$.

\begin{tabular}{cccccccc}
\hline Time $(\mathbf{h})$ & Rat 1 & Rat 2 & Rat 3 & Rat 4 & Rat 5 & AVE & SD \\
\hline 0.5 & $5.9 *$ & 27.6 & 17.8 & 17.1 & 12.7 & 16.2 & 0.49 \\
1 & $6.6 *$ & 29.3 & 37.2 & 11.8 & $10.7 *$ & 19.1 & 0.70 \\
2 & 12.6 & 63.1 & 94.5 & 85.0 & 15.2 & 54.1 & 0.71 \\
4 & 29.5 & 122.2 & 129.7 & 183.8 & 53.3 & 103.7 & 0.60 \\
6 & 45.7 & 129.5 & 237.4 & 148.0 & 122.3 & 136.6 & 0.50 \\
7 & 71.4 & 237.4 & 340.8 & 401.1 & 131.3 & 236.4 & 0.58 \\
8 & 109.6 & 285.6 & 285.5 & 381.8 & 261.3 & 264.8 & 0.37 \\
10 & 234.0 & 199.9 & 226.5 & 88.0 & 181.2 & 185.9 & 0.32 \\
12 & 55.0 & 44.9 & 108.2 & 104.4 & 131.6 & 88.8 & 0.42 \\
14 & 69.1 & 84.7 & 87.9 & 110.4 & 107.5 & 91.9 & 0.19 \\
24 & $1.0 *$ & 51.1 & $5.9 *$ & $10.9 *$ & $6.3 *$ & 15.0 & 1.36 \\
27 & 11.6 & $10.6 *$ & 0.0 & $2.7 *$ & $6.2 *$ & $6.2 *$ & 0.80 \\
30 & 13.6 & $11.0 *$ & $11.0 *$ & $5.8 *$ & $9.6 *$ & $10.2 *$ & 0.28 \\
36 & $3.5 *$ & $1.8 *$ & $1.8 *$ & 0.0 & $3.2 *$ & $2.0 *$ & 0.68 \\
48 & $0.4 *$ & $2.3 *$ & $1.7 *$ & $1.6 *$ & 0.0 & $1.2 *$ & 0.81 \\
\hline \multicolumn{7}{c}{$* 0.0$}
\end{tabular}

Table 15. Concentration time of TA-III after intragastrical administration to rats at a dose of $75 \mathrm{mg} / \mathrm{kg}(\mathrm{ng} / \mathrm{mL})$.

\begin{tabular}{cccccccc}
\hline Time (h) & Rat1 & Rat 2 & Rat 3 & Rat 4 & Rat 5 & AVE & SD \\
\hline 0.5 & 0.0 & 26.3 & 0.0 & 0.0 & 0.0 & $5.3 *$ & 2.24 \\
1 & 30.1 & 38.2 & $2.6 *$ & $9.4 *$ & $2.8 *$ & 16.6 & 0.99 \\
2 & 15.1 & 38.2 & 11.6 & 42.0 & 20.2 & 25.4 & 0.54 \\
4 & 54.6 & 63.2 & 8.0 & 61.1 & 51.9 & 47.8 & 0.47 \\
6 & 170.1 & 71.7 & 48.9 & 274.2 & 71.9 & 127.3 & 0.74 \\
7 & 304.2 & 180.0 & 104.3 & 357.5 & 414.1 & 272.1 & 0.47 \\
8 & 546.1 & 298.7 & 363.0 & 607.3 & 583.3 & 479.7 & 0.29 \\
10 & 300.8 & 305.0 & 196.9 & 350.9 & 247.3 & 280.2 & 0.21 \\
\hline
\end{tabular}


Table 15. Cont.

\begin{tabular}{cccccccc}
\hline Time (h) & Rat1 & Rat 2 & Rat 3 & Rat 4 & Rat 5 & AVE & SD \\
\hline 12 & 141.6 & 156.4 & 117.1 & 181.0 & 99.1 & 139.0 & 0.23 \\
14 & 121.1 & 104.9 & 121.9 & 88.9 & 60.7 & 99.5 & 0.26 \\
24 & 51.8 & 67.0 & 22.1 & 59.8 & 103.5 & 60.8 & 0.48 \\
27 & 37.9 & 31.5 & 19.8 & 50.5 & 22.2 & 32.4 & 0.38 \\
30 & 49.2 & 142.5 & $6.4 *$ & 13.1 & 22.6 & 46.8 & 1.20 \\
36 & $12.7 *$ & 12.7 & 26.9 & 16.3 & 31.5 & 20.0 & 0.43 \\
48 & $5.6 *$ & $6.8 *$ & $8.8 *$ & $3.0 *$ & 12.5 & $7.3 *$ & 0.49 \\
\hline \multicolumn{7}{c}{ * Represents the detected concentrations below LLOQ. }
\end{tabular}

Figure 5. Plasma concentration-time curves of TA-III after intragastric administration to rats at dose of 25,50 and $75 \mathrm{mg} / \mathrm{kg}$.

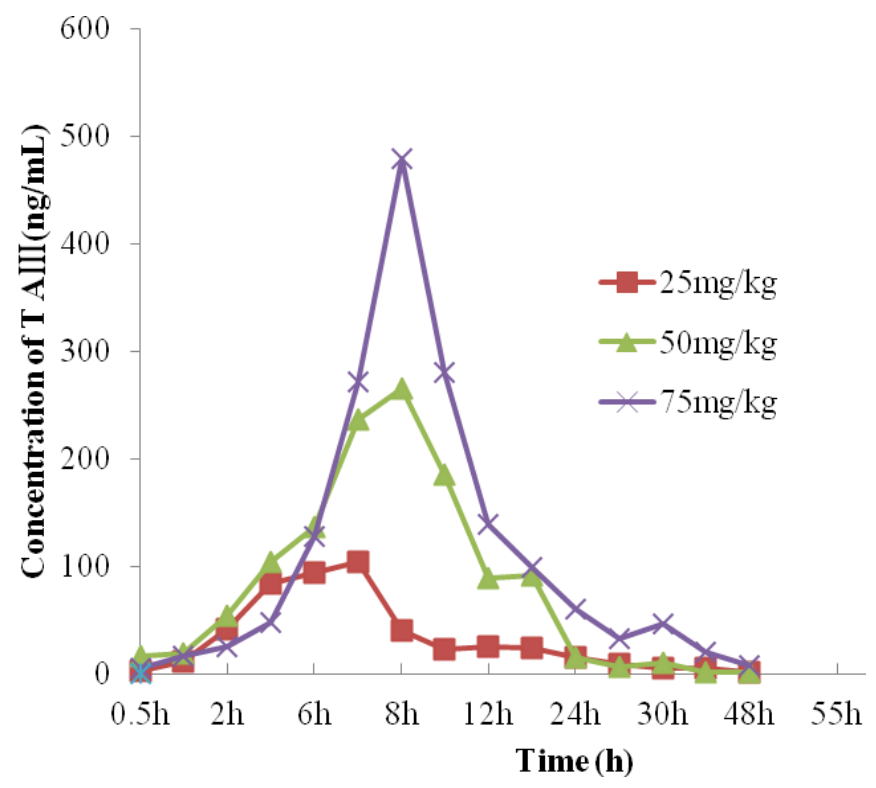

Table 16. Pharmacokinetic parameters of TA-III after intragastrical administration to rats at a dose of $25 \mathrm{mg} / \mathrm{kg}$.

\begin{tabular}{ccccccc}
\hline Parameters & Rat1 & Rat 2 & Rat 3 & Rat 4 & Rat 5 & MEAN \pm SD \\
\hline $\mathrm{T}($ peak $)(\mathrm{h})$ & 7 & 6 & 7 & 7 & 7 & $6.8 \pm 0.4$ \\
$\mathrm{C}(\mathrm{max})(\mathrm{ng} / \mathrm{mL})$ & 100.7 & 97.5 & 93.2 & 131 & 106.3 & $105.7 \pm 14.9$ \\
$\mathrm{Ke}(1 / \mathrm{h})$ & 0.352 & 0.374 & 0.051 & 0.274 & 0.419 & $0.294 \pm 0.146$ \\
$\mathrm{Ka}(1 / \mathrm{h})$ & 0.407 & 0.416 & 0.984 & 0.314 & 0.472 & $0.519 \pm 0.166$ \\
$\mathrm{t}_{1 / 2}(\mathrm{ka})(\mathrm{h})$ & 1.703 & 1.665 & 0.704 & 2.209 & 1.47 & $1.55 \pm 0.546$ \\
$\mathrm{t}_{1 / 2}(\mathrm{~h})$ & 1.969 & 1.854 & 5.693 & 2.528 & 1.653 & $2.74 \pm 1.68$ \\
$\mathrm{MRT}(0-\infty)(\mathrm{h})$ & 9.35 & 9.051 & 19.842 & 13.592 & 8.421 & $12.1 \pm 4.8$ \\
$\mathrm{AUC}(0-\infty)[(\mathrm{ng} / \mathrm{mL}) \mathrm{h}]$ & 766.1 & 729.6 & 1347.2 & 1093.9 & 672.1 & $921.8 \pm 289.0$ \\
\hline
\end{tabular}


Table 17. Pharmacokinetic parameters of TA-III after intragastrical administration to rats at a dose of $50 \mathrm{mg} / \mathrm{kg}$.

\begin{tabular}{ccccccc}
\hline Parameters & Rat1 & Rat 2 & Rat 3 & Rat 4 & Rat 5 & MEAN \pm SD \\
\hline $\mathrm{T}($ peak $)(\mathrm{h})$ & 10 & 8 & 7 & 7 & 8 & $8 \pm 1.2$ \\
$\mathrm{C}(\max )(\mathrm{ng} / \mathrm{mL})$ & 234 & 285.6 & 340.8 & 401.1 & 261.3 & $304.6 \pm 66.8$ \\
$\mathrm{ke}(1 / \mathrm{h})$ & 0.279 & 0.195 & 0.205 & 0.3 & 0.209 & $0.238 \pm 0.048$ \\
$\mathrm{ka}(1 / \mathrm{h})$ & 0.343 & 0.218 & 0.238 & 0.354 & 0.238 & $0.278 \pm 0.065$ \\
$\mathrm{t}_{1 / 2}(\mathrm{ka})(\mathrm{h})$ & 2.022 & 3.175 & 2.912 & 1.958 & 2.91 & $2.60 \pm 0.56$ \\
$\mathrm{t}_{1 / 2}(\mathrm{~h})$ & 2.482 & 3.556 & 3.38 & 2.313 & 3.311 & $3.01 \pm 0.57$ \\
$\mathrm{MRT}(0-\infty)(\mathrm{h})$ & 12.226 & 11.663 & 9.877 & 10.122 & 11.304 & $11.038 \pm 1.007$ \\
$\mathrm{AUC}(0-\infty)[(\mathrm{ng} / \mathrm{mL}) \mathrm{h}]$ & 1395.4 & 2682.6 & 3300.0 & 2694.1 & 2347.9 & $2484.0 \pm 698.8$ \\
\hline
\end{tabular}

Table 18. Pharmacokinetic parameters of TA-III after intragastrical administration to rats at a dose of $75 \mathrm{mg} / \mathrm{kg}$.

\begin{tabular}{ccccccc}
\hline Parameters & Rat1 & Rat 2 & Rat 3 & Rat 4 & Rat 5 & MEAN \pm SD \\
\hline $\mathrm{T}($ peak $)(\mathrm{h})$ & 8 & 10 & 8 & 8 & 8 & $8.4 \pm 0.9$ \\
$\mathrm{C}(\max )(\mathrm{ng} / \mathrm{mL})$ & 546.1 & 305 & 363 & 607.3 & 583.3 & $480.9 \pm 137.4$ \\
$\mathrm{Ke}(1 / \mathrm{h})$ & 0.386 & 0.088 & 0.313 & 0.364 & 0.548 & $0.340 \pm 0.166$ \\
$\mathrm{Ka}(1 / \mathrm{h})$ & 0.567 & 0.332 & 0.496 & 0.571 & 0.7 & $0.533 \pm 0.134$ \\
$\mathrm{t}_{1 / 2}(\mathrm{ka})(\mathrm{h})$ & 1.222 & 2.088 & 1.396 & 1.213 & 0.991 & $1.382 \pm 0.420$ \\
$\mathrm{t}_{1 / 2}(\mathrm{~h})$ & 1.794 & 7.908 & 2.216 & 1.902 & 1.264 & $3.017 \pm 2.756$ \\
$\mathrm{MRT}(0-\infty)(\mathrm{h})$ & 14.236 & 17.46 & 19.741 & 12.753 & 16.889 & $16.216 \pm 2.754$ \\
$\mathrm{AUC}(0-\infty)[(\mathrm{ng} / \mathrm{mL}) \mathrm{h}]$ & 2938.3 & 4081.9 & 1992.8 & 3432.8 & 2424.3 & $2974.07 \pm 822.2$ \\
\hline
\end{tabular}

Table 19. Pharmacokinetic parameters of TA-III after intragastrical administration to rats at different dose.

\begin{tabular}{cccc}
\hline Parameters & $\mathbf{2 5} \mathbf{~ m g} / \mathbf{k g}$ & $\mathbf{5 0} \mathbf{~ m g} / \mathbf{k g}$ & $\mathbf{7 5} \mathbf{~ m g} / \mathbf{k g}$ \\
\hline $\mathrm{Ke}(1 / \mathrm{h})$ & $0.294 \pm 0.146$ & $0.238 \pm 0.048$ & $0.340 \pm 0.166$ \\
$\mathrm{Ka}(1 / \mathrm{h})$ & $0.519 \pm 0.166$ & $0.278 \pm 0.065$ & $0.642 \pm 1.393$ \\
$\mathrm{t}_{1 / 2}(\mathrm{ka})(\mathrm{h})$ & $1.55 \pm 0.546$ & $2.60 \pm 0.56$ & $1.382 \pm 0.420$ \\
$\mathrm{t}_{1 / 2}(\mathrm{~h})$ & $2.74 \pm 1.68$ & $3.01 \pm 0.57$ & $3.02 \pm 2.76$ \\
$\mathrm{~T}(\mathrm{peak})(\mathrm{h})$ & $6.8 \pm 0.4$ & $8 \pm 1.2$ & $8.4 \pm 0.9$ \\
$\mathrm{C}(\mathrm{max})(\mathrm{ng} / \mathrm{mL})$ & $105.7 \pm 14.9$ & $304.6 \pm 66.8$ & $480.9 \pm 137.4$ \\
$\mathrm{AUC}[(\mathrm{ng} / \mathrm{mL}) \mathrm{h}]$ & $921.8 \pm 289.0$ & $2484.0 \pm 698.8$ & $2974.07 \pm 822.2$ \\
$\mathrm{MRT}(\mathrm{h})$ & $12.1 \pm 4.8$ & $11.0 \pm 1.0$ & $16.2 \pm 2.8$ \\
\hline
\end{tabular}

\section{Conclusions}

The LC-MS/MS method for determining TA-III in biological samples was in accordance with the guidance on bioanalysis criteria in methodological investigation. The method had been successfully used for pharmacokinetic studies of TA-III with intragastrical administration in rats. The concentration of TA-III for up to $48 \mathrm{~h}$ after administration of TA-III could be detected for all groups with different doses. In the statistical process, it was found that the best fit pharmacokinetic model to estimate the pharmacokinetic parameters was a single compartment model with the weight of $1 / x^{2}$ for oral 
administration groups of rats by using DAS 2.0 software. The results showed that C (max) of TA-III was mainly dependent on the dose with the coefficient of correlation of 0.9988 in the three groups. AUC of TA-III has a bad relationship with the dose with the coefficient of a correlation of 0.9166 . The half-lives $\left(t_{1 / 2}\right)$ were $1.55 \pm 0.546,2.60 \pm 0.56$ and $1.382 \pm 0.420 \mathrm{~h}$, which demonstrated that the elimination of TA-III was relatively quick. Mean residence time (MRT) was 12.1 $\pm 4.8,11.0 \pm 1.0$ and $16.2 \pm 2.8 \mathrm{~h}$, thereby revealing the body retention time of this compound was long, and indicating, in turn, that TA-III was difficult to be absorbed, but easy to be eliminated in rats. These pharmacokinetic properties will have inevitable influences on its biological effects.

\section{Acknowledgements}

This work was financially supported by National Natural Science Foundation of China (Project Number: 81173561), Foundation of the Ministry of Education of China (NCET-10-0944), Shanghai Municipal Education Commission Project (Project Number: J50302, 10SG40).

\section{References}

1. Lee, B.; Jung, K.; Kim, D.H. Timosaponin AIII, a saponin isolated from Anemarrhena asphodeloides, ameliorates learning and memory deficits in mice. Pharmacol. Biochem. Behav. 2009, 93, 121-127.

2. Sy, L.-K.; Yan, S.-C.; Lok, C.-N.; Man, C.N.; Che, C.M. Timosaponin A-III induces autophagypreceding mitochondria-mediated apoptosis in HeLa cancer cells. Cancer Res. 2008, 68, 10229-10237.

3. King, F.W.; Fong, S.; Griffin, C.; Shoemaker, M.; Staub, R.; Zhang, Y.-L.; Cohen, I.; Shtivelman, E. Timosaponin AIII is preferentially cytotoxic to tumor cells through inhibition of mTOR and induction of ER stress. PLoS One 2009, 4, e7283.

4. Youn, U.J.; Jang, J.-E.; Nam, J.-W.; Lee, Y.J. Son, Y.M.; Shin, H.J.; Han, A.-R.; Chang, J.; Seo, E.-K. Anti-respiratory syncytial virus (RSV) activity of timosaponin A-III from the rhizomes of Anemarrhena asphodeloides. J. Med. Plants Res. 2011, 5, 1062-1065.

5. Lok, C.-N.; Sy, L.-K.; Liu, F.L.; Che, C.-M. Activation of Autophagy of Aggregation-prone Ubiquitinated Proteins by Timosaponin A-III. J. Biol. Chem. 2011, 286, 31684-31696.

6. Cai, F.; Sun, L.N.; Gao, S.H.; Yang, Y.; Yang, Q.; Chen, W.S. A rapid and sensitive liquid chromatography-tandem mass spectrometric method for the determination of timosaponin B-II in blood plasma and a study of the pharmacokinetics of saponin in the rat. J. Pharm. Biomed. Anal. 2008, 48, 1411-1416.

7. Ma, B.P.; Dong, J.X.; Wang, B.J.; Yan, X.Z. Study on the furostanol saponin from rhizoma anemarrhenae. Acta Pharm. Sini. 1996, 31, 271-277.

(C) 2013 by the authors; licensee MDPI, Basel, Switzerland. This article is an open access article distributed under the terms and conditions of the Creative Commons Attribution license (http://creativecommons.org/licenses/by/3.0/). 